\title{
A study for allocating resources to research and development programs by integrated fuzzy DEA and fuzzy AHP
}

\author{
Chun-Chu Liu \\ Department of International Business, Chang Jung Christian University, Taiwan, R.O.C. P. O. Box 6-15 Tainan, Tainan \\ County, Taiwan 717, R.O.C. E-mail: Icc@mail.cjcu.edu.tw. \\ Accepted 15 November, 2010
}

\begin{abstract}
A decision model is developed to help managers select the most appropriate sequences of plans for product research and development (R\&D) projects under strict constraints on budget and resources. In recent years, many organizations have changed from discipline-oriented to focusing on integrated programs and related outcomes. For a decision-maker of these high-profile R\&D programs, it is critical to understand which activities are the most important, considering both investment feasibility and cost-effectiveness. This paper proposes a two-dimensional decision model that integrates fuzzy data envelopment analysis and analytic hierarchy process to perform this essential task. Using the information from these two decision science tools, the model develops a two-axis evaluation space for research alternatives. By locating particular activities in this decision space, a program manager can compare and prioritize alternative research investments.
\end{abstract}

Key words: Fuzzy data envelopment analysis, fuzzy analytic hierarchy process, research and development.

\section{INTRODUCTION}

A large corporation often has to make decisions on the scope of product research and development (R\&D) projects. The main criteria for project evaluation are budget and resources constraints. Therefore, the selection of a balanced $R \& D$ portfolio, combining corporation goals, resources and constraints is an important but venturesome task (Islei et al., 1991). Research portfolio analysis and decision models can be effective tools in promoting organizational participation in complex decision-making. This involvement develops a consensus for and understanding of organizational goals and the associated performance metrics. To achieve the goal, decision models should provide managerial information without the distraction of excessive complexity (Howard, 1988). Specifically, models should provide benefits that exceed the difficulty and effort required for model development, use and maintenance. This study proposes integrating two complementary decision tools that have particular promise in $R \& D$ management environment: fuzzy analytic hierarchy process (FAHP) and data envelopment analysis (FDEA). Major concerns in the two-dimensional decision model are comparing, prioritizing alternative research investments and the best allocation of the corporation's resources to selected projects. Specifically, the 'two-dimensional model' incorporates the following features:

1) The 'model' makes use of the subjective information provided by FAHP and the objective information from FDEA.

2) The 'model' helps managers choose the "right" project. This choice requires an understanding of which $R \& D$ project has the greatest potential to create value for the corporation and the difficulty of achieving it (Menke, 1991). A "right" project is a project with relatively high chance of success and low development cost.

3) A resource allocation plan to help managers perform the development process "right." Such a plan requires managers to organize tasks and resources to work on the most valuable project attributes and surmount technical hurdles in the most timely and cost-effective way.

The rest of the paper is organized as follows: subsequently, 


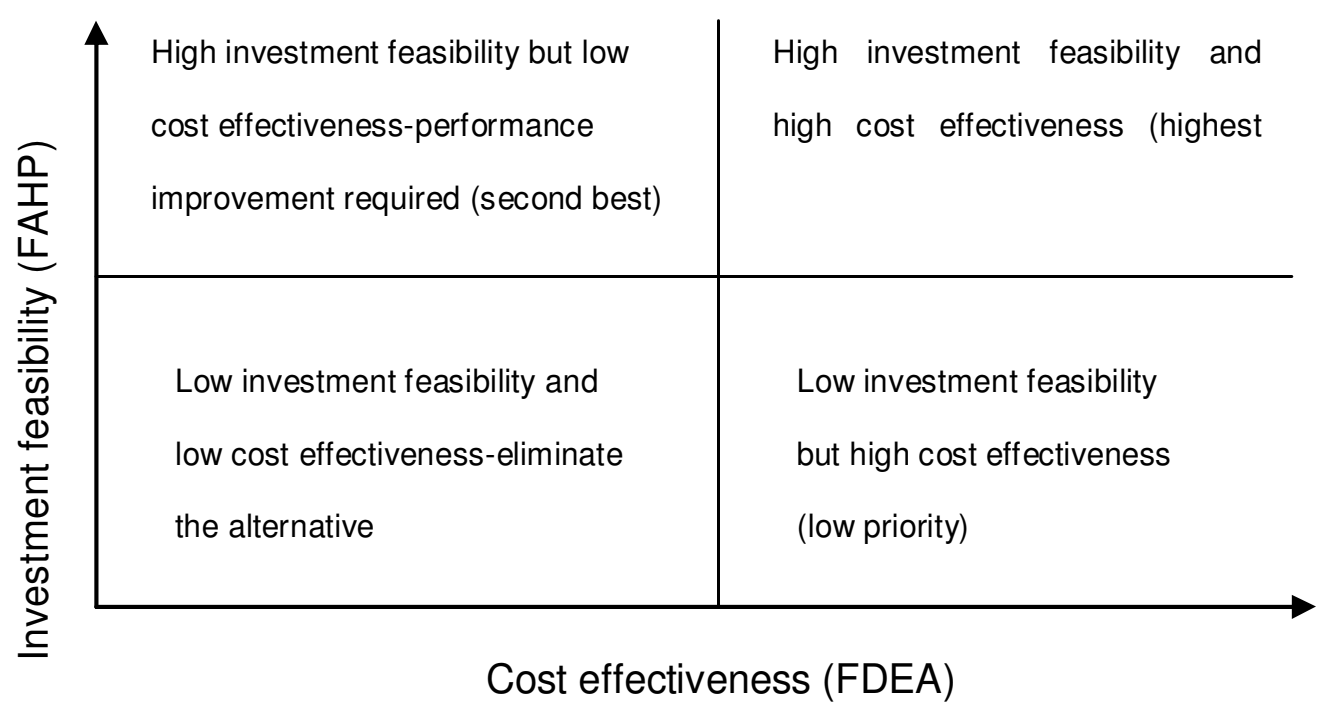

Figure 1. Two-Dimensional decision space.

it describes the related literature, after which the proposed two-dimensional decision model is presents. There after it describes the application of the proposed model. Lastly, the conclusion of the paper is given.

\section{MATERIALS AND METHODS}

The management of a balanced development portfolio is a typical resource allocation problem in an $R \& D$ environment where a company can pursue only a limited number of research projects and the chance of success of some of the projects is highly uncertain. There is a vast literature on $R \& D$ project evaluation and selection, and there are hundreds of models using a wide range of mathematically based approaches (Baker and Pound, 1964; Schroder, 1971; Baker and Freeland, 1971; Albala, 1975; Liberatore and Titus, 1986; Souder and Tomislav, 1986; Roussell et al., 1991; Poth and Bai, 2001; Osawa and Michikazu, 2002; Meade and Presley, 2002). Various researchers have provided a good review of these approaches to R\&D project management. However, very few have focused on examining the degree to which the techniques meet the requirements of the evaluation process (Poth et al., 2001). According to Poth et al. (2001) study results which reveal weighting and ranking methods are better than benefit-contribution methods. The most common types of weighting and ranking methods are the comparative method, scoring method, DEA and AHP. We can further divide the aforementioned methods into subjective and objective decision methods depending on the information provided. Subjective decision methods determine weights and ranks that reflect subjective judgment, but the decision-makers can influence these weights. Objective decision methods determine weights and ranks by making use of mathematical models, but they neglect subjective judgment. Subjective decision methods involve subjectivity when determining the R\&D investment alternatives; it has better rationality with respect to determining the priority of the $R \& D$ investment alternatives. Therefore, the subjective decision methods should enjoy the highest priority in choosing among the R\&D investment alternatives, followed by objective decision methods. It is also important for decision-makers to minimize the practice of subjective judgment in order to minimize decision errors. The comparative method and scoring method are popular methods for ranking $R \& D$ projects, but have severe drawbacks. R\&D alternatives are usually a decision of multiple criteria or multiple objectives. Because FAHP involves analysis, it is ideal for evaluating investment feasibility.

The AHP method has been applied to R\&D project evaluation (Poth et al., 2001; Liberatore, 1987; Goldern et al., 1989), while the DEA method is useful for ranking $R \& D$ projects and it is effective in identifying inefficient R\&D projects (Linton et al., 2002). Cost effectiveness evaluation can be made using DEA. This study combines both the subjective decision method (FAHP) and the objective decision method (FDEA) to evaluate R\&D investment alternatives using the decision space shown in Figure 1. The X-Axis in Figure 1 stands for cost effectiveness evaluation while $Y$-axis stands for investment feasibility evaluation. The figure is divided into four quadrants and then each quadrant is subdivided into four more quadrants and vice versa. It means the alternative that falls in the top right corner has the advantage of being cost-effective and investment-feasible. Investors may have the R\&D projects chosen and ranked with top priority in the said figure. The first quadrant stands for high investment feasibility and cost effectiveness-highest priority. The second quadrant stands for high investment feasible but not cost effectiveness-performance improvement required (second best). The third quadrant stands for low investment feasible and cost effectiveness-eliminate the alternative. The fourth quadrant stands for low investment feasible but cost effectiveness-low priority.

\section{RESULTS AND DISCUSSION}

Here, provides a simple example of FDEA in a research management context and integration with FAHP to evaluate research activities in the subjective and objective decision space involving success feasibility and productivity (Figure 1). Consider a decision-maker faced with allocating limited funding for R\&D program goals and objectives. Ten R\&D activities are candidates for funding to support program objectives. Firstly, to clearly illustrate the FDEA concept, percentage completion is the only output and each R\&D project is assessed according to 
Table 1. Inputs and outputs of $10 \mathrm{R} \& \mathrm{D}$ projects unit: million.

\begin{tabular}{|c|c|c|c|c|}
\hline \multirow{2}{*}{ R\&D alternatives } & \multirow{2}{*}{ Output (\% complete) } & \multicolumn{2}{|c|}{ Inputs } & \multirow{2}{*}{ Total budgets } \\
\hline & & Labor cost & Capital cost & \\
\hline A1 & 100 & 1 & 200 & \\
\hline A2 & 100 & 2 & 250 & \\
\hline A3 & 100 & 3 & 225 & \\
\hline A4 & 100 & 4 & 125 & \\
\hline A5 & 100 & 5 & 150 & \\
\hline A6 & 100 & 6 & 150 & 500 \\
\hline A7 & 100 & 7 & 120 & \\
\hline A8 & 100 & 8 & 80 & \\
\hline A9 & 100 & 9 & 100 & \\
\hline A10 & 100 & 10 & 40 & \\
\hline
\end{tabular}

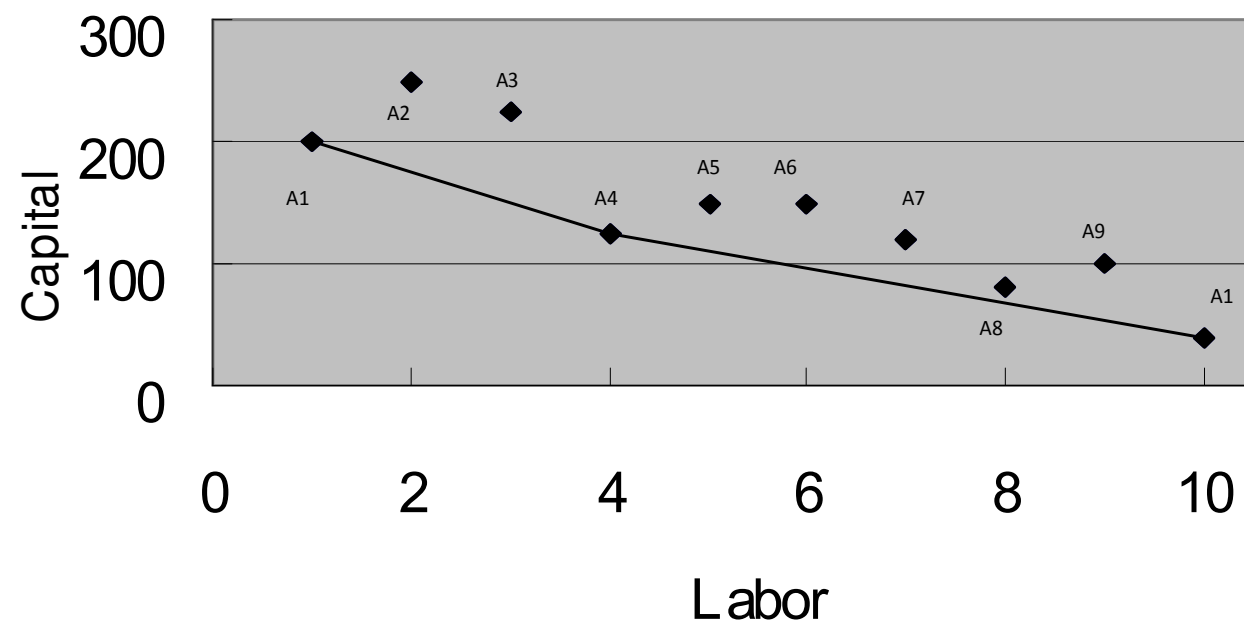

Figure 2. Productivity frontier of the 10 alternatives.

the input resources (here are labor and capital) required to achieve $100 \%$ completion. Table 1 presents a summary of the inputs, outputs and total budgets for the $10 R \& D$ projects. Since a uniform output has been selected and two inputs are used in the example, an easily interpreted graphical representation can be developed to provide insight into the FDEA results. Figure 2 plots the input data for the R\&D alternatives and shows that the productivity frontier is composed of $A 1, A 4$ and $A 10$ while the rest are not as efficient and are beyond the frontier. Secondly, the FAHP is employed to evaluate the successful feasibility of $R \& D$ investment alternatives. According to the evaluation criteria of the investment project, the technical evaluation criteria derived from a previous study (Ta, 1989; Osawe et al., 2002 ) is referred for investment evaluation. Evaluation criteria include the feasibility of markets, technology, economic and finance. Feasibility analysis of markets is to search and analyze the data used in confirming, identifying, illustrating, and quantifying markets in order to determine whether a market is sufficient now and in the future for our investment project and whether it is a profitable investment. Feasibility analysis of technology is to confirm whether the investment project is technically possible for execution; moreover, for the reference of cost evaluation. Feasibility analysis of economy applies the result of market analysis and technology analysis to analyzing the economic effect of an investment project in accordance with the concept of financial statements and cash flow; as well as for estimating operating performance in order to understand the economic effect of the investment project. Feasibility analysis of finance is for expressing the value of investment project from the standpoint of profit, in other words, to evaluate the possible combinations of investment fund source and fund cost. Figure 3 shows the FAHP hierarchy for our investment alternatives. Our objective is to perform a comparative study of the 10 investment alternatives. These 10 investment alternatives are enumerated at level 3 of the hierarchy in Figure 3. At the highest level of the hierarchy, we specify the goal, which is the identification of the successful feasible R\&D investment alternatives. 


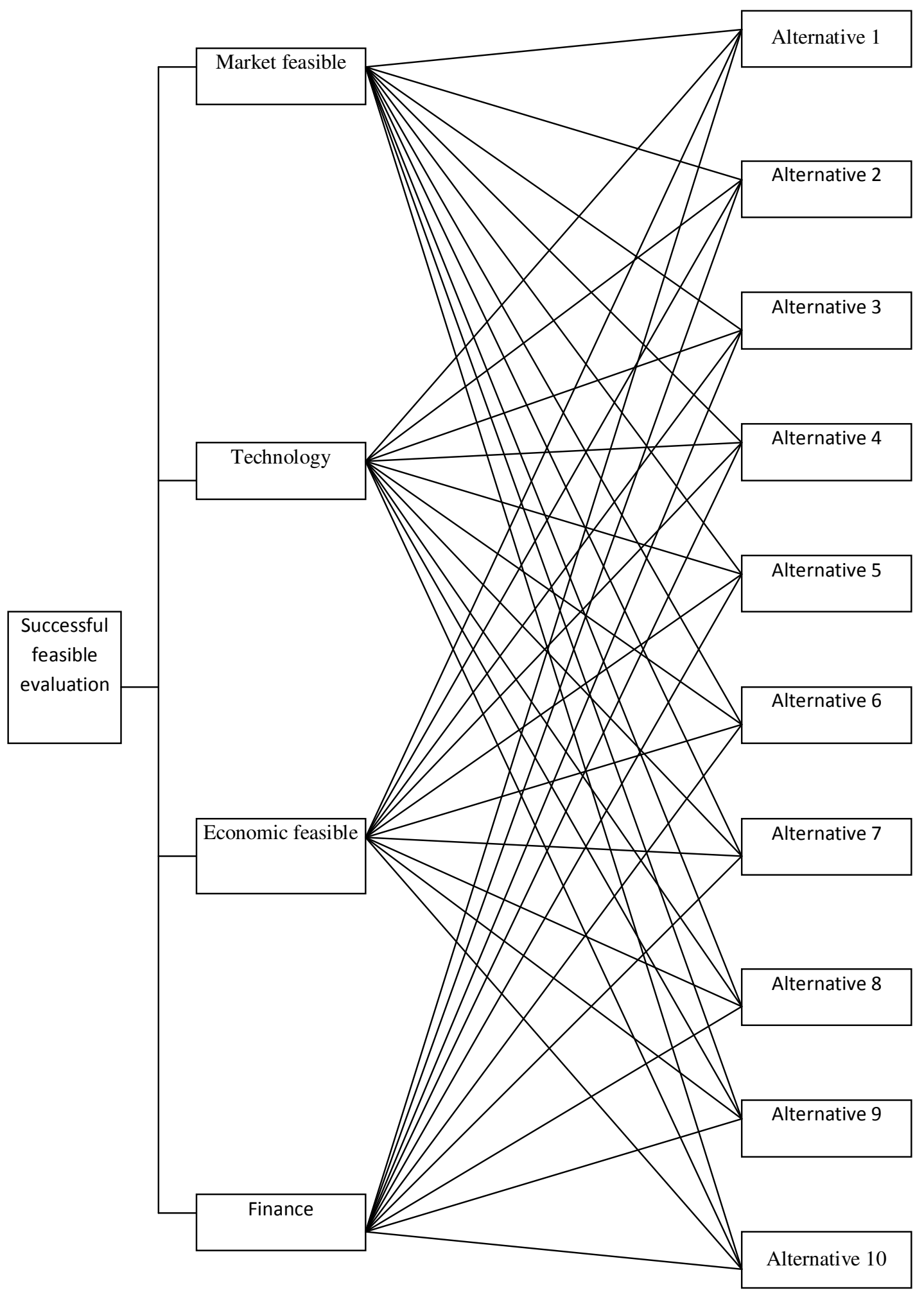

Figure 3. FAHP hierarchy evaluation of investment feasibility.

Level 2 of the hierarchy lists four major criteria that are critical in determining the effectiveness of R\&D investment alternatives. Level 3 of the hierarchy lists the
10 investment alternatives. Both the FAHP-developed successful feasible ratings and the FDEA objective function values for the R\&D alternatives are plotted in 


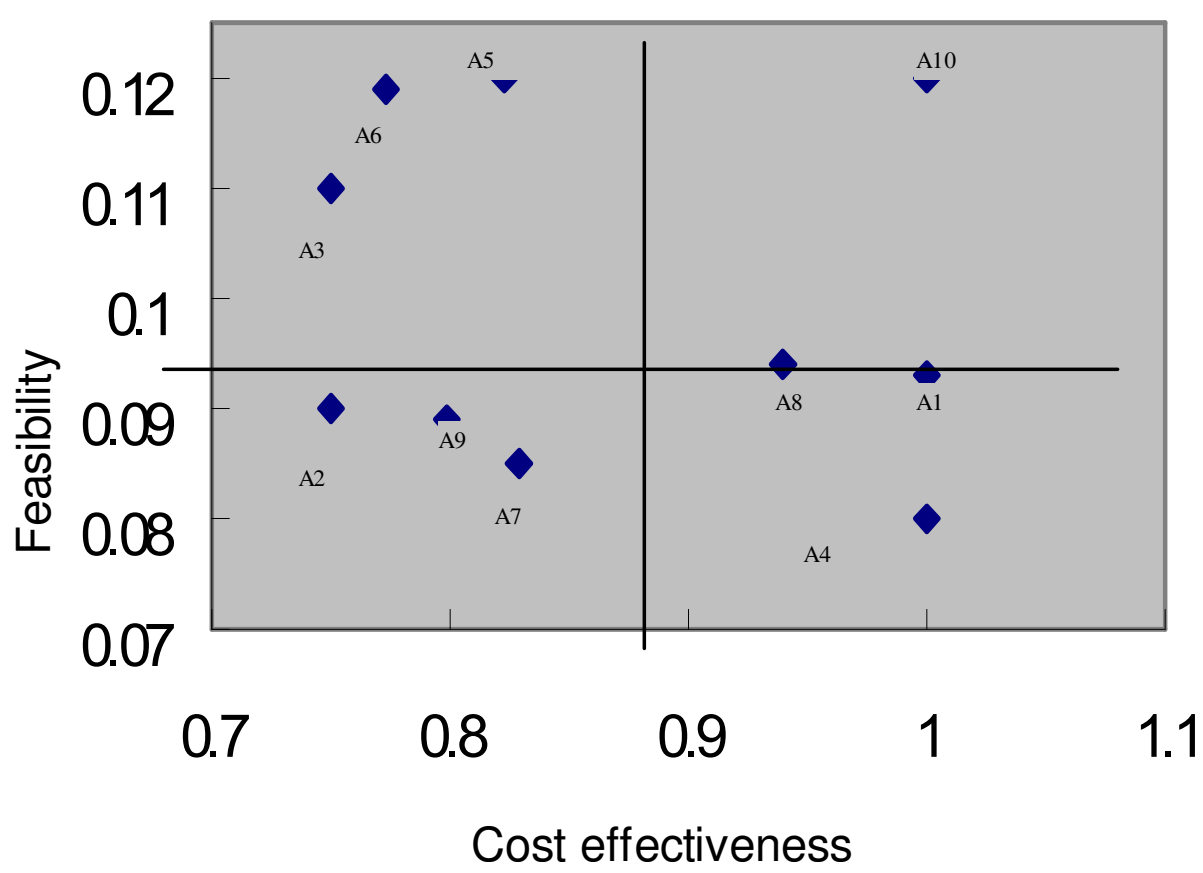

Figure 4. Two-dimensional decision space.

Table 2. Summary of FDEA and FAHP values.

\begin{tabular}{ccc}
\hline R\&D alternatives & Investment feasibility from FAHP method & Cost effectiveness from FDEA method \\
\hline A1 & 0.073 & 1.00000 \\
A2 & 0.09 & 0.75 \\
A3 & 0.11 & 0.75 \\
A4 & 0.08 & 1.00000 \\
A5 & 0.16 & 0.82264 \\
A6 & 0.109 & 0.77305 \\
A7 & 0.075 & 0.82890 \\
A8 & 0.094 & 0.93966 \\
A9 & 0.089 & 0.79853 \\
A10 & 0.12 & 1.00000 \\
\hline
\end{tabular}

Figure 4. According to the four-quadrant analysis, the decision-maker can draw the following conclusions:

1) R\&D A10 is both productive and feasible. This is a very high-priority project.

2) R\&D A1, A4 and A8 are productive but not feasible. As a result, this program has a low priority for funding.

3) R\&D A2, A7 and A9 should be eliminated. They are not productive and not important.

4) $R \& D A 3, A 5$ and $A 6$ should be targeted for improvement if possible. It is an important program but not cost-effective compared with other programs.

5) The priority of the $10 \mathrm{R} \& \mathrm{D}$ alternatives is in the order of $\mathrm{A} 10, \mathrm{~A} 5, \mathrm{~A} 6, \mathrm{~A} 3, \mathrm{~A} 1, \mathrm{~A} 8, \mathrm{~A} 4, \mathrm{~A} 9, \mathrm{~A} 7$ and $\mathrm{A} 2$.

In view of the limited budget (NT\$5 million), decision-makers should adopt A10, A5, and A6 but not A3.

\section{Conclusion}

This study introduces a two-dimensional decision model, a planning and scheduling tool that helps decision-maker evaluate and analyze schedules and resource requirements for $R \& D$. By building on the strengths of two simple, yet powerful, decision tools, the model employs FAHP and FDEA (Table 2) to develop a decision space that identifies critical impact areas for decision-makers. Using FAHP, the model identifies the feasible activities that can achieve organizational goals. FDEA identifies the activities that are cost-effective and thereby brings 
the reality of limited budgetary resources into the decision process. Together, these two data elements allow the decision-maker to evaluate and compare research alternatives in a two-dimensional space. In short, the two-dimensional model incorporates the following features:

1) This model reduces subjective judgment.

2) A scientific and systematic product development process to help managers choose the "right" project.

3) A resource allocation plan to help managers perform the development process "right."

4) The flexibility of this model makes possible a wide range of application opportunities.

\section{ACKNOWLEDGMENT}

The author would like to thank the National Science Council of the Republic of China for financially supporting this research under Contract No. 96-2416-H-309-005-.

\section{REFERENCES}

Albala A (1975). Stage Approach for the Evaluation and Selection of R\&D Projects, IEEE Trans. Eng. Manage., 22: 153-164.

Baker NR, Freeland JR (1971). Recent Advantages in R\&D Benefit Measurement and Project Selection Methods, Manage. Sci., 21: 1164-1175.

Baker NR, Pound WH (1964). R\&D Project Selection: Where do We Stand? IEEE Transactions on Eng. Manage., 21: 124-134.
Goldern B, Wasil EA, Harker PT (eds) (1989). The Analytic Hierarchy Process: Applications and Studies. Berlin: Springer-Verlag.

Howard RA (1988). Decision Analysis: Practice and Promise, Manage. Sci., 34: 679-695.

Islei G, Lockett G, Cox B, Stratford M (1991). A Decision Support System Using Judgment Modeling: A Case of R\&D in the Pharmaceutical Industry, IEEE Trans. Eng. Manage., 38: 202-209.

Liberatore MJ (1987). An Extension of the Analytic Hierarchy Process for Industrial R\&D Project Selection and Resource Allocation. IEEE Trans. Eng. Manage., 34(4): 2-18.

Liberatore ML, Titus GJ (1986). Managing Industrial R\&D Project: Current Practice and Future Direction, J. Soc. Res. Admin. 18: 5-12.

Linton JD, Walsh ST, Morabito J (2002). Analysis, Ranking and Selection of $R \& D$ Projects in a Portfolio, $R \& D$ Management, 32: 139-148.

Meade LM, Presley A (2002). R\&D project selection using the analytic network process, IEEE Trans. Eng. Manage., 49: 59-66.

Menke M (1991). Tools for Improving the Quality of R\&D Management, Technology Management, The New International Language, Kocaoglu, D.F. and Niwa, K. (eds.), New York, NY, pp.162-165.

Osawa Y, Michikazu M (2002). Development and application of a new methodology of evaluating industrial R\&D projects, $R \& D$ Management, 32: 79-86.

Poth KL, Ang BW, Bai $F$ (2001). A comparative analysis of R\&D project evaluation methods, R\&D Management, 31: 63-75.

Roussell PA, Kamal NS, Tamara JE (1991). Third Generation R \& D Management: the Link to Corporate Strategy, Harvard Business School Press.

Schroder H (1971). R\&D Project Evaluation and Selection Models for Development: A Survey of the State of the ART, Socio-Econ. Plan Sci., 5, 25-39.

Souder WE, Tomislav M (1986). R \& D Project Selection Models, Res. Manage., 29: 136-42.

Ta FJ (1989). Project Evaluation, Hwa-Tai Press. (In Chinese). 